\title{
Methodology of Designing Disassembly and Reassembly Processes Using Lean Thinking Approach
}

\author{
Tomasz Kanikuła and Tomasz Koch \\ Centre for Advanced Manufacturing Technologies (CAMT), \\ Institute of Production Engineering and Automation, \\ Wroclaw University of Technology, Poland \\ www. itma.pwr.wroc.pl
}

\begin{abstract}
In this paper a conception of using Lean Manufacturing methodology in disassembly and reassembly processes (Remanufacturing) is presented. Nine scenarios of material and information flows in Remanufacturing processes were developed in order to cover most of possible real situations.
\end{abstract}

Keywords: Remanufacturing, Lean Manufacturing, Pull System, Lean Remanufacturing.

\section{Introduction}

This paper presents some results of the research project funded by Polish Ministry of Research and Higher Education (4 T07D 004 29). Aim of this research project is to prepare transparent and adaptable methodology of designing disassembly and reassembly processes using Lean Thinking approach. The project required a review on current best industrial practices in managing and organization of remanufacturing processes. At the beginning literature review of current state of the art in Remanufacturing was carried out. The objective of the next step was to examine which Lean tools and methods could be applied in Remanufacturing system design and therefore could be incorporated into Lean Remanufacturing methodology. Simultaneously data were collected from industry to understand how disassembly and reassembly are organized in various industries. Several Remanufacturing companies were visited in order to carry out observations of current practices and to carry out interviews by using special questionnaire. The next step was to develop generic Lean Remanufacturing methodology in collaboration with one of remanufacturing companies from automotive sector. This way practical point of view for the research work was ensured and each element of elaborated methodology could be at least conceptual tested.

\subsection{Remanufacturing}

Remanufacturing is an industrial process where used products are restored to useful life. Remanufacturing consist of disassembling (sometimes with first inspection), cleaning, inspection, repairing (with inspection of $100 \%$ parts), replacing and reassembling (with final tests) the components of part or product in order to return it to 
like-new condition. In some Remanufacturing processes there are operations that are not needed in other. Examples are: galvanization, additional inspection and tests.

Remanufacturing is often confused with repair or overhaul, but it has to be underline that remanufacturing is different than refurbishing, overhaul or repair. Remanufacturing can also offer additional economic and environmental benefits because it recaptures approximately $85 \%$ [3] of the labour and energy that comprise the "value added" content.

\section{Lean Remanufacturing - Methodology}

The aim of applying lean into remanufacturing processes is to increase efficiency of remanufacturing businesses. Therefore several research studies on this topic have been already undertaken in recent years $[6,7,8]$. Those studies identify problems of Lean implementations trials in Remanufacturing e.g.:

- not every remanufacturing operation is needed in each remanufacturing process,

- difficulties in definition of takt time for remanufacturing systems (not always consumer demand is known)

- cycle times varies and it depends on quality or repeatability of incoming products,

- quantity of disassembled parts varies and it also depends on quality or repeatability of incoming products,

- diversity in range of products,

- possible huge amount of core (used products) inventory waiting for disassembly,

- sometimes no high-runners.

In order to respond to those problems a new Lean Remanufacturing methodology is proposed, and will be described in further parts of this paper.

\subsection{Research Limitations}

Several boundary conditions for developed methodology was defined like:

- full availability of cores

- technology of disassembly is known

- technology of reassembly is known

- rate of using new parts is known

- methods of supplying new parts are the same in each nine scenarios.

For future research all of nine scenarios of material and information flows developed within Lean Remanufacturing methodology should be analyzed and tested in real industrial environment in order of further improvement and fine tuning.

\subsection{Lean Remanufacturing - Where to Start?}

Remanufacturing is a specific environment, where the range of products is usually very wide. The first thing that have to be done is to chose pilot area to implement Lean conception. The tool that could be used to chose the best product family to start from is Glenday Sieve [4]. This tool separates products (SKU's) into four groups based on sales volume (or value if this is more appropriate). Typical result is presented in Table 1 [4]. 
Table 1. Glenday Sieve

\begin{tabular}{|c|c|}
\hline$\%$ Cumulative Sales & \% Product Range \\
\hline $50 \%$ & $6 \%$ \\
\hline $95 \%$ & $50 \%$ \\
\hline $99 \%$ & $70 \%$ \\
\hline $1 \%$ & $30 \%$ \\
\hline
\end{tabular}

The first steps in the proposed methodology is to use Glenday Sieve to separate 6\% of product range that are responsible for $50 \%$ of the sales volume. These products families will be the pilot area to start implementing Lean. Second step will be to chose one of nine scenarios suggested. To be able to do this, it is recommended to use table 2 .

Table 2. Matching scenario with current Remanufacturing condition

\begin{tabular}{|l|c|c|c|c|c|c|c|c|c|}
\hline \multirow{2}{*}{ Features of Remanufacturing: } & \multicolumn{9}{|c|}{ Scenarios } \\
\cline { 2 - 3 } & $\mathbf{1}$ & $\mathbf{2}$ & $\mathbf{3}$ & $\mathbf{4}$ & $\mathbf{5}$ & $\mathbf{6}$ & $\mathbf{7}$ & $\mathbf{8}$ & $\mathbf{9}$ \\
\hline Instability of repair cycle time & $\bullet$ & $\bullet$ & & & & $\bullet$ & & $\bullet$ & $\bullet$ \\
\hline Instability of disassembly cycle time & & $\bullet$ & $\bullet$ & & $\bullet$ & $\bullet$ & $\bullet$ & $\bullet$ & $\bullet$ \\
\hline Unstable recovery percentage at repair & $\bullet$ & $\bullet$ & & & & $\bullet$ & & $\bullet$ & $\bullet$ \\
\hline Unstable recovery percentage at disassemble & & $\bullet$ & $\bullet$ & & $\bullet$ & $\bullet$ & $\bullet$ & $\bullet$ & $\bullet$ \\
\hline Not enough place for core (used products) & & & & & & & $\bullet$ & $\bullet$ & $\bullet$ \\
\hline Disassembled parts inventory recommended & & $\bullet$ & $\bullet$ & & $\bullet$ & $\bullet$ & & & \\
\hline Repaired parts inventory recommended & $\bullet$ & $\bullet$ & & & & $\bullet$ & & $\bullet$ & $\bullet$ \\
\hline Finished products inventory recommended & & & & $\bullet$ & $\bullet$ & $\bullet$ & & & \\
\hline No need to control disassembly process & & & & & & & $\bullet$ & $\bullet$ & $\bullet$ \\
\hline Repair is expensive and time consuming & & & $\bullet$ & $\bullet$ & $\bullet$ & & $\bullet$ & & \\
\hline Disassemble is expensive and time consuming & $\bullet$ & & & $\bullet$ & & & & & \\
\hline High cost of finished products inventory & $\bullet$ & $\bullet$ & $\bullet$ & & & & $\bullet$ & $\bullet$ & $\bullet$ \\
\hline Different cycle time in each process & & $\bullet$ & & & & $\bullet$ & & $\bullet$ & $\bullet$ \\
\hline
\end{tabular}

In the table 2, the most important features of Remanufacturing process were listed. These should be carefully analyzed to chose the most appropriate scenario. Black points indicate the most adequate scenario that could be applied to particular feature (problem). It should be noticed that some of Remanufacturing problems could be solved by more than one scenario.

\subsection{Nine Scenarios}

During this project several alternative solutions were identified and described to enable using Lean approach in such specific area like Remanufacturing. Techniques and methods such as One Piece Flow, Pull System, Visual Control, Kanban System, SMED, TPM, Kaizen, Glenday Sieve, Value Stream Mapping, PFEP were examined. Nine scenarios (graphics symbols based on "Learning to See" [5]) that make use of some of those methods in Remanufacturing were developed in order to cover most of possible real situations. 


\section{Scenario 1 - Supermarket of repaired parts}

Each core that is delivered to Remanufacturing company should be stored in core warehouse, waiting for signal to be disassembled. Customer orders should be collected at reassembly. Based on them, proper parts have to be picked up from supermarket, reassembled (with new parts also) and shipped to customer according to FIFO rule. Replenishment pull signal (kanban) is sent from supermarket to disassembly to inform: what, when, and where needs to be disassembled (Fig. 1).

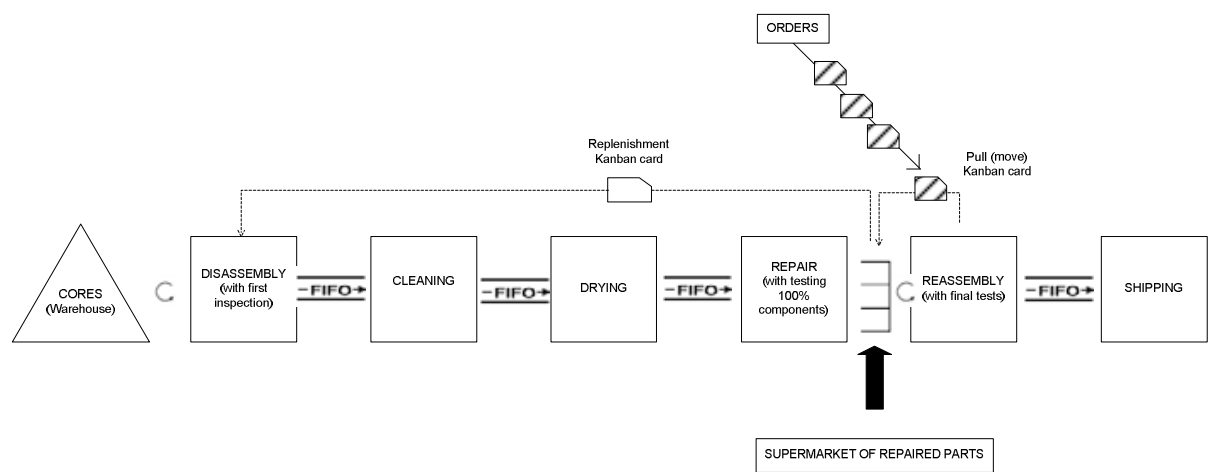

Fig. 1. Scenario 1 with Supermarket of repaired parts

\section{Scenario 2 - Two supermarkets for disassembled and repaired parts}

Each core that is delivered to Remanufacturing company should be stored in core warehouse, waiting for a signal to be disassembled. Customer orders should be collected at reassembly. Based on them, proper parts have to be picked up from supermarket of repaired parts, reassembled (together with new parts) and shipped to customer according to FIFO rule. First, pull system (1) sends an information (kanban) to repair: what, when, and where has to be replenished in supermarket of repaired parts (Fig. 2). Repair process takes the parts from supermarket of disassembled parts. Second, pull system (2) sends information signal to disassembly: what, when, and where needs to be replenished in supermarket of disassembled parts.

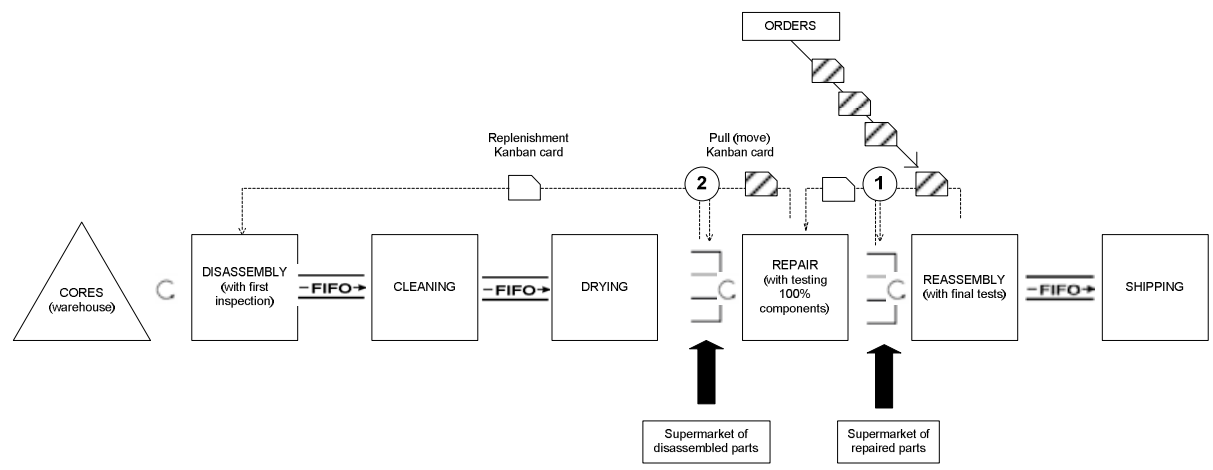

Fig. 2. Scenario 2 with two supermarkets for disassembled and repaired parts 


\section{Scenario 3 - Supermarket of disassembled parts}

Each core that is delivered to Remanufacturing company should be stored in core warehouse, waiting for signal to be disassembled. Customer orders should be collected at reassembly. Based on them, proper parts have to be picked up from supermarket, repaired, reassembled (together with new parts) and shipped to customer according to FIFO rule (Fig. 3). Pull system sends an information (kanban) to disassembly: what, when, and where needs to be replenished.

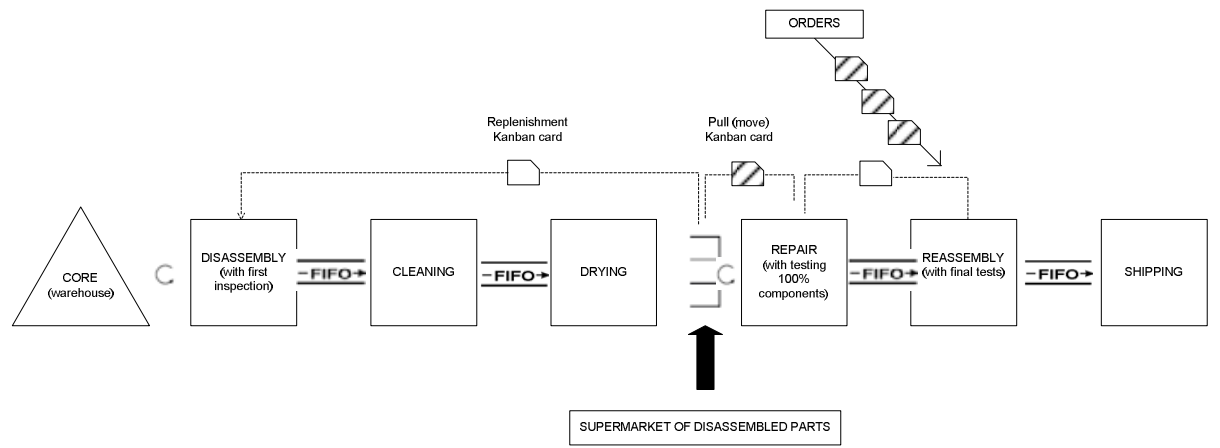

Fig. 3. Scenario 3 with Supermarket of disassembled parts

\section{Scenario 4 - Supermarket of finished products}

Each core that is delivered to Remanufacturing company should be stored in core warehouse, waiting for signal to be disassembled. Customer orders should be collected at shipping. Based on them, proper products have to be picked up from supermarket and sent to customer. Pull system sends an information (kanban) to disassembly: what, when, and where needs to be replenished (Fig. 4).

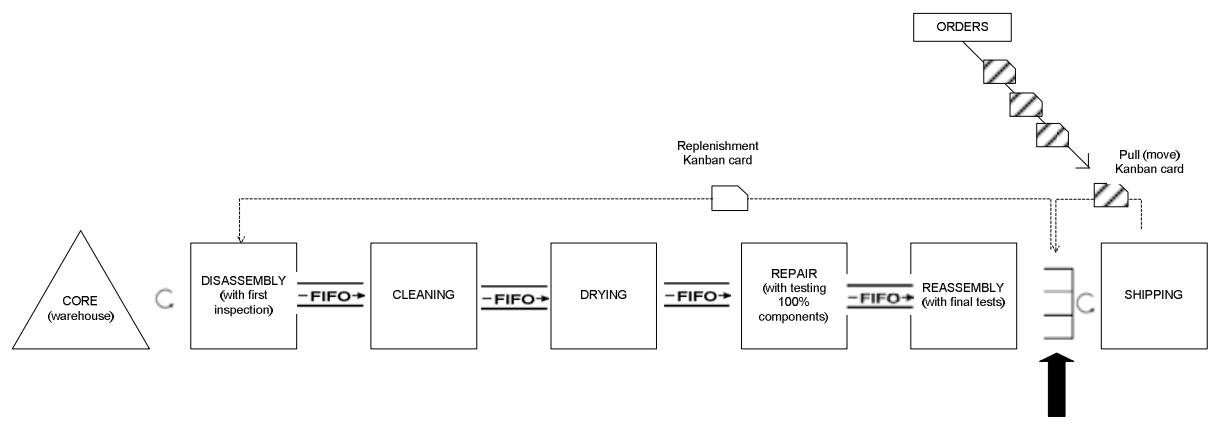

SUPERMARKET OF FINISHED PRODUCTS

Fig. 4. Scenario 4 with Supermarket of finished products

\section{Scenario 5 - Two supermarkets for disassembled parts and finished products}

Each core that is delivered to Remanufacturing company should be stored in core warehouse, waiting for a signal to be disassembled. Customer orders should be collected at shipping. Based on them, proper parts have to be picked up from finished products supermarket and sent to customer. First, pull system (1) sends an information 
(kanban) to repair: what, when, and where needs to be repaired in order to replenish finished parts supermarket (Fig. 5). Repair process takes parts from supermarket of disassembled parts. Second, pull system (2) sends information to disassembly: what, when, and where needs to be replenished in supermarket of disassembled parts.

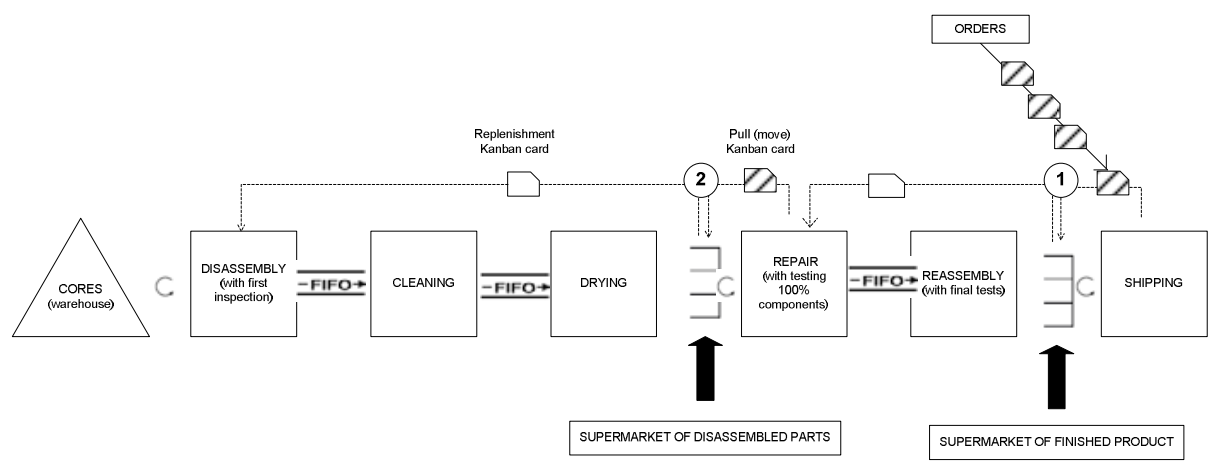

Fig. 5. Scenario 5 with two supermarkets for disassembled parts and finished products

Scenario 6 - Fixed sequence and volume cycle in disassembly and repair processes

For $6 \%$ of product range both, the sequence and volumes in the cycle, should be fixed. What to do next in disassembly and repair processes should be determined by the cycle. The aim of this fixed cycle is to create economies of repetition that generate several benefits [4]. Both "buffer tanks" with control limits (Fig. 6) absorb the variability between demand and supply e.g. between repair and disassembly. If the level of parts is between control limits the plan is still fixed. Reassemble process should collect orders, based on them, assemble products (together with new parts) and ship them to customers.

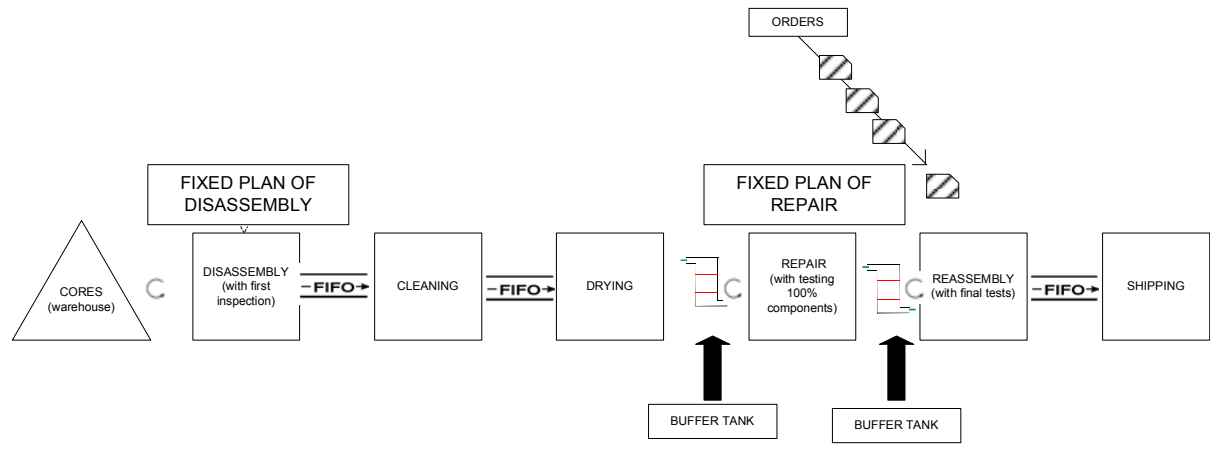

Fig. 6. Scenario 6 with Fixed sequence and volume cycle in disassembly and repair processes

\section{Scenario 7 - Warehouse of Disassembled Parts \& sequential pull system from repair to shipping}

Each core that is delivered to Remanufacturing company has to be disassembled immediately on arrival. When order appears in reassembly process, required parts are picked up from warehouse of disassembled parts. Next step is to repair, reassemble (together with new parts) and ship according to FIFO rule (Fig. 7). 


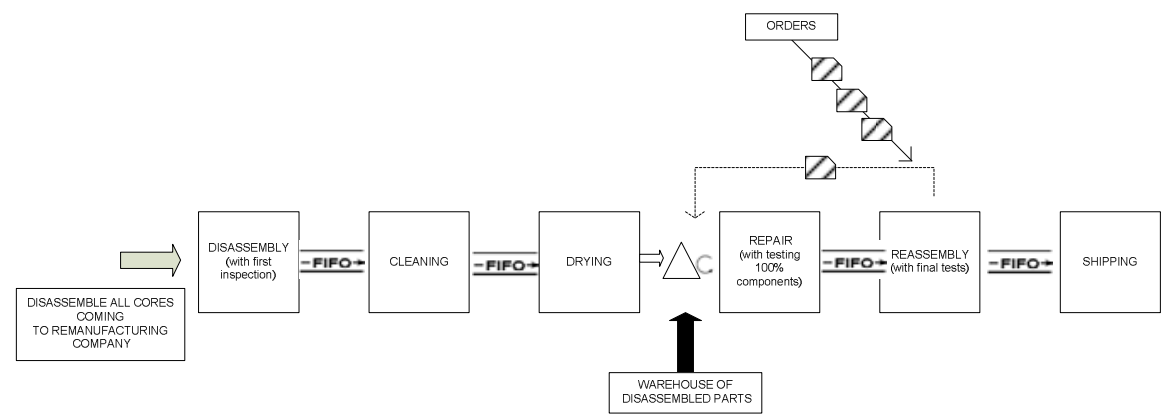

Fig. 7. Scenario 7 with Warehouse of disassembled parts \& sequential pull system from repair to shipping

\section{Scenario 8 - Warehouse of disassembled parts \& Supermarket of repaired parts}

Each core that is delivered to Remanufacturing company has to be disassembled immediately on arrival. When order appears in reassembly process, required parts are picked up from Supermarket of repaired parts, reassembled (together with new parts) and shipped to customer according to FIFO rule (Fig. 8). Parts, that are taken from Supermarket have to be replenished by repair process.

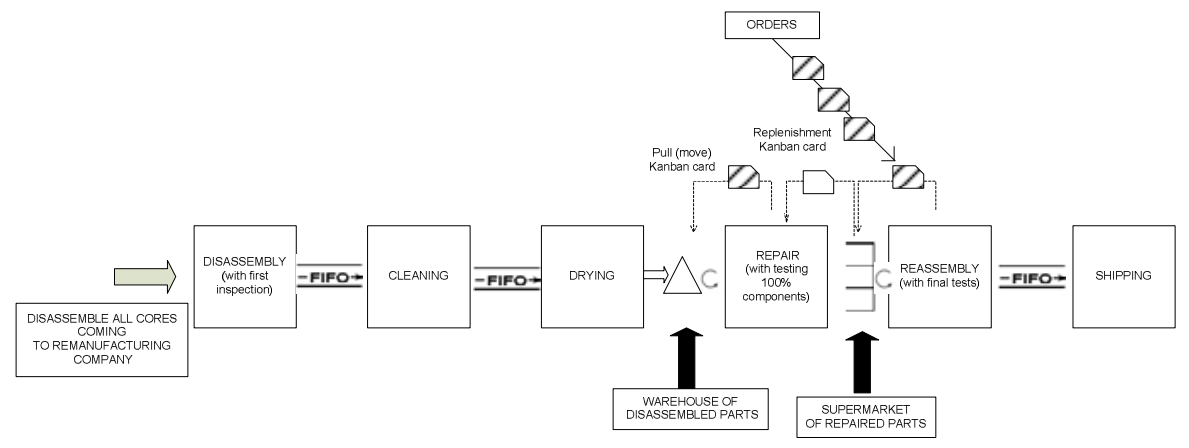

Fig. 8. Scenario 8 with Warehouse of disassembled parts \& Supermarket of repaired parts

\section{Scenario 9 - Warehouse of disassembled parts \& Fixed sequence and volume in repair process}

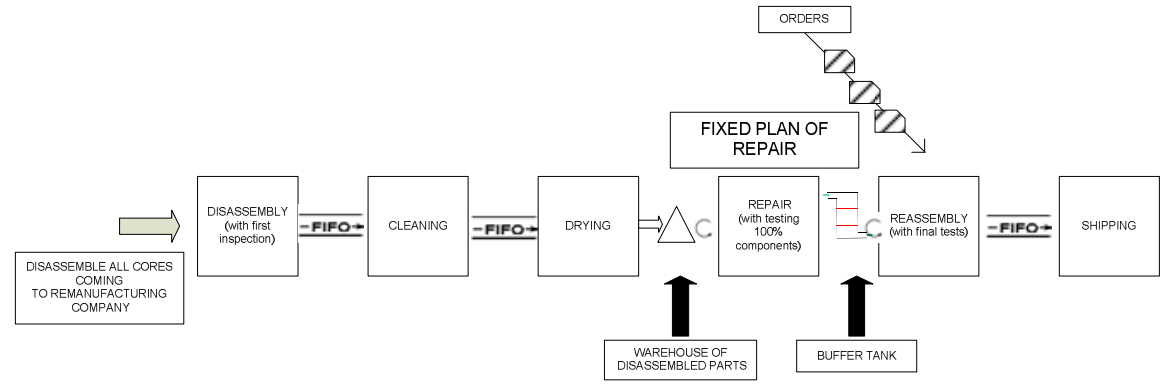

Fig. 9. Scenario 9 with Warehouse of disassembled parts \& Fixed sequence and volume in repair process 
Each core that is delivered to Remanufacturing company has to be disassembled immediately on arrival. Fixed (sequence and volume) plan of repairing has to be designed. After repair process there is a "buffer tank" with control limits. It absorbs the variability between demand (reassembly) and supply (repair). If the level of repaired parts is between control limits the plan is still fixed. Reassemble process collects orders, based on them, assemble products (together with new parts) and ship them to customers.

\section{Expected Results and Conclusion}

Desired result of implementing Lean Remanufacturing methodology:

- improvement of consumer service (reduced number of complains),

- improvement of Lead Time (time between order and shipping to customer),

- decrease of finished products stock,

- decrease of value of new parts in remanufactured products,

- decrease in number of cores that have to be disassembled to remanufacture ordered number of products,

- reduced space needed for cores,

- reassembly process has always available parts for preparing consumers orders,

- ability to manage changing orders, flexibility.

- fixed sequence and volume gives potential for economies of repetition,

- no delays in repair process caused by awaiting for disassembled parts.

In this paper a vital part of new and original methodology of using Lean Thinking approach in Remanufacturing was presented. Several alternative solutions were identified and described. The methodology development intention was to make it useful for every Remanufacturing company, which aim of implementing Lean Thinking is something more than only eliminating waste.

\section{References}

1. Smalley, A.: Creating Level Pull, pp. 13-69. The Lean Enterprise Institute, Brookline (2004)

2. Womack, J., Jones, D.T.: Lean Thinking. Simon \& Schuster, New York (1996)

3. Nasr, N.Z.: Remanufacturing from Technology to Applications. In: Proceedings Global Conference on Sustainable Product Development and Life Cycle Engineering, Berlin (2004)

4. Glenday, I.: Breaking through to flow. Lean Enterprise Academy, Ross-on-Wye (2007)

5. Rother, M., Shook, J.: Learning to See. The Lean Enterprise Institute, Brookline (1998)

6. Kagan, R.: Lean Solutions for Remanufacturing Systems? In: Proceedings Polish-German Workshop on Lean Remanufacturing, Oficyna Wydawnicza Politechniki Wroclawskiej, Wroclaw (2006)

7. Mähl, M., Östlin, J.: Lean Remanufacturing - Material Flow at Volvo Parts Flen. Master Thesis, Department of Business Studies, Upsala University (2006)

8. Dunkel, M.: Methodenentwicklung für Lean Remanufacturing. Shaker Verlag, Aachen (2008) 